\title{
Effect of Blade Type, Cutting Velocity and Stalk Cross Sectional Area of Black Gram Stalks on Cutting Energy and Cutting Force
}

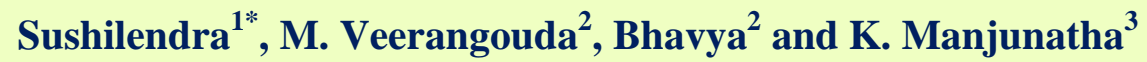 \\ ${ }^{1}$ Department of Farm Machinery and Power Engineering, College of Agricultural \\ Engineering, University of Agricultural Sciences, Raichur, Karnataka, India \\ ${ }^{2}$ Department of Agricultural Engineering, College of Agricultural Engineering, \\ University of Agricultural Sciences, Raichur, Karnataka, India \\ ${ }^{3}$ Farm Machinery \& Power, ICAR-Directorate of Cashew Research, Puttur, Karnataka, India \\ *Corresponding author
}

\section{A B S T R A C T}

\begin{tabular}{|l|}
\hline Ke y w o r d s \\
Black gram, Cutting \\
energy, Cutting \\
force, Harvesting, \\
Threshing
\end{tabular}

A study was under taken to investigate the effect of blade type, cutting velocity and cross sectional area of stalks on cutting energy and cutting force required for cutting of black gram stalks. A laboratory test rig consisting of a pendulum type impact tester was designed and developed to measure the cutting energy. The bundled black gram stalks were fitted firmly in the stalk holder to simulate natural stand of stalk in the field. Two types of blades viz., smooth edge and serrated types were used for the present study. The experimental results showed that the cutting energy and cutting force requirement were increased as the cross sectional area of black gram stalks increased whereas these values were decreased as the cutting velocity increased for both type of blades. Serrated type blade required less cutting energy and cutting force as compared to that of smooth edge type blade at all diameter of stalks and cutting velocities.

\section{Introduction}

The variation in the physical properties of plant stalks and the resistance of cutting have to be known in order to understand the behaviour of material with respect to different operating conditions of harvesting and threshing. Increased interest in mechanized crop harvesting and commercial use of straw has prompted the need for engineering data on stem properties (Yore et al., 2002). Comparative performance of cutting elements applied in harvester design can be judge by their cutting energy requirements, cutting force and stress applied (Chakraverty et al., 2003).

Hence, it is necessary to determine the cutting 
energy requirements for suitable knife design and also operational parameters. Mantesh (2006) developed a cutter bar test rig for recording the dynamic force required for cutting black gram, black gram and green gram stalks. He concluded that cutting force increased with increase in the diameter of stalks. Many researchers have reported on the cutting strength of the plant stem and effective parameters on cutting energy for different crops. Their results showed that the cross-sectional area and moisture content of the crop had significant effect on cutting energy and maximum cutting force (Yilmaz et al., 2008). Kathirvel et al., (2009) revealed that the peak cutting requirement was directly proportional to stalk diameter and inversely proportional to moisture content of stalk and cutter bar speed. The cutter bar with stroke length $90.00 \mathrm{~mm}$ registered 6.30 to $28.70 \%$ reduction in peak cutting force as compared to $76.20 \mathrm{~mm}$ stroke length for the selected levels of cutter bar speeds, diameter and moisture content of maize stalk. Dauda et al., (2015) reported that the cutting speed had significant effect on cutting torque and cutting power requirements. The cutting speed was directly proportional to the specific cutting power, while the cutting torque was inversely proportional to the moisture content.

Traditionally, harvesting and threshing of black gram crop is done by manual method. After harvest, the plants are left in the field and later threshed by animals or tractor treading. It results in considerable loss and poor quality of grain. The present situation of migration of the labour force to various scholastic jobs leads non availability of agricultural labourers. This situation necessitates the introduction of a suitable machine for harvesting and threshing of black gram. So in order to aid in the engineering design refinement of machine for harvesting of black gram crop, it is essential to investigate the effects of blade parameters such as blade cutting speed and blade type on the cutting characteristics of black gram crop stems viz., cutting energy and cutting force.

With the above points in view, a pendulum impact tester was fabricated to study the effect of blade cutting speed and type of blade on the cutting energy and cutting force requirement of selected variety of black gram crop variety viz., T-9 which is commonly grown in Karnataka state.

\section{Materials and Methods}

A pendulum impact tester was fabricated (Plate 1) and it consists of platform, main frame, pendulum arm, pendulum shaft, dial gauge, stalk holder, blade holder and blade both serrated or smooth edge type (Fig. 1).

A platform to support the pendulum impact tester was fabricated using mild steel sheet of $4 \mathrm{~mm}$ thickness with dimensions of $930 \times 920$ $\mathrm{mm}$. The surface of the platform was horizontal and was $170 \mathrm{~mm}$ above the ground level with the help of stand made from $35 \mathrm{x}$ $35 \mathrm{x} 4 \mathrm{~mm}$ angle iron.

In order to provide support and structural stability to the components of the pendulum impact tester, a main frame was fabricated using $50 \times 50 \times 4 \mathrm{~mm}$ angle iron. It was designed in triangular shape with dimensions of $1210 \mathrm{~mm}$ in height, side lengths of 625 $\mathrm{mm}$, base length of $920 \mathrm{~mm} \&$ the distance between centre of triangle to the base was 450 $\mathrm{mm}$.

A long pendulum arm was suspended at its top end (from a pivot point) and had a knife fixed at lower end and was made to oscillate freely in vertical plane with the help of a support shaft passing through two pedestal (No. P205) bearings at either end resting on top portion of the main frame. When a pendulum was displaced sideways from its 
resting equilibrium position, it was subjected to a restoring force due to gravity that will accelerate it back towards the equilibrium position. When released, the restoring force combined with the pendulum's mass causes it to oscillate about the equilibrium position, swinging back \& forth. Pendulum arm was made up of rectangular mild steel bar of $980 \mathrm{x}$ $25 \times 12 \mathrm{~mm}$ dimensions. At top two $70 \mathrm{~mm}$ bush having an internal diameter of $250 \mathrm{~mm}$ was welded. The total weight of pendulum arm was $3 \mathrm{~kg}$.

In pendulum impact tester dial gauge was used to determine the deflection angle of pendulum arm. Dial gauge consists of two pointer and graduated angular scale. Dial gauge angular scale was marked on a mild steel sheet of $300 \mathrm{~mm}$ diameter and mounted on the pendulum shaft. Two pointers of 100 $\mathrm{mm}$ length were fabricated and one is mounted on pendulum arm and other is mounted on pendulum shaft. Dial gauge was used to see the displacement of pendulum arm before and after cutting of the stalk.

Stalk holder was used to hold the stalk for cutting. A bench vice made up of cast iron was used as stalk holder, which would prevent sliding of the stalk during the experiment. The bench vice was bolted to holder frame. The size of the stalk holder frame was $260 \mathrm{~mm}$ length, $170 \mathrm{~mm}$ width and height of $150 \mathrm{~mm}$ and was fitted to platform. Stalk holder could slide on the frame for adjusting the cutting position.

Blade holder was used for accommodating the blade on pendulum arm. It was fabricated using mild steel flats. The length of blade holder was about $104 \mathrm{~mm}$ with a width of 25 $\mathrm{mm}$. It was provided with bolt for tightening the blades. Two types of blades viz., smooth edged and serrated type, as used in cutter bar of combine harvester, were used for determining cutting energy and cutting force.
Experiments were conducted at four levels of blade velocity and four levels of stem cross sectional area (or diameter). The response parameters measured during the experiment were cutting energy and cutting force. The variables considered for study are listed in Table 1.

\section{Blade velocity}

When the blade is released, its initial velocity is zero. But when it reaches the stem placed vertically downward position, it has the highest velocity based on physics laws on cutting moment. The relation between peripheral velocity $\left(\mathrm{V}_{\mathrm{c}}\right)$ and initial angle (dropping angle) of a pendulum arm at the impact moment was calculated from the following equation (Koloor, 2007):

$$
\mathbf{V}_{\mathbf{c}}=\frac{\sqrt{2 W R(1-\square \square \square \cos (1)}}{I} \mathrm{~L}
$$

Where,

$$
\mathrm{W}=\text { Weight of pendulum, } \mathrm{N}
$$

$\mathrm{R}=$ Distance between the rotational centre and centre of gravity, $\mathrm{m}$

$\mathrm{I}=$ Moment of inertia, $\mathrm{kg} \mathrm{m}^{2}$

$\mathrm{L}=\quad$ Length of pendulum, $\mathrm{m}$.

\section{Cutting energy}

The material to be cut was placed at the point of maximum kinetic energy of the swinging arm and held by the stalk holder. When the arm was released, it gains speed till it meets and cuts the material placed in the path of the knife. The difference in the angle before and after cutting will be directly related to energy consumed for cutting of the stalk. The energy required for cutting of black gram plant stalk was determined by using the following expression.

$\mathrm{E}_{\mathrm{c}}=\operatorname{mgR}\left(\cos \theta_{1}-\cos \theta_{2}\right)$

Where, 


$$
\begin{aligned}
& \mathrm{E}_{\mathrm{c}}=\text { Cutting energy, } \mathrm{J} \\
& \mathrm{m}=\text { Mass of the pendulum, } \mathrm{kg} \\
& \mathrm{g}=\text { Gravitational acceleration, } \\
& \mathrm{m} / \mathrm{s}^{2}=\text { Radial length to centre of } \\
& \mathrm{R}=\text { Angle of pendulum at initial } \\
& \text { gravity, } \mathrm{m} \text { and } \\
& \theta_{1}=\text { A A } \\
& \text { position, degrees } \\
& \theta_{2}=\text { Angle of pendulum after } \\
& \text { cutting, degrees }
\end{aligned}
$$

\section{Cutting force}

Cutting force was calculated by measuring the cutting energy and dividing length of which is equivalent to diameter of the stalk.

$$
F_{c}=\frac{E_{c}}{D}
$$

Where,

$\mathrm{F}_{\mathrm{c}} \quad=\quad$ Cutting force, $\mathrm{N}$

$\mathrm{E}_{\mathrm{c}}=$ Cutting energy, $\mathrm{J}$

$\mathrm{D}=$ Diameter of the stem, $\mathrm{mm}$

Data was analyzed to detect significant differences by ANOVA at a significance level of 0.01 and 0.05 . The software used for ANOVA procedure was Design Expert 7.0.0 for windows. The standard deviation and coefficient of variation were also calculated for above experiment.

The black gram plant samples were chosen randomly in the field. Samples of the stalks were removed from the ground level \& brought to the laboratory and used for determining the stalk diameter. During the experiment, the stalks of black gram plants were bundled to get desired cross sectional area of 113, 200, 314 and $452 \mathrm{~mm}^{2}$. The corresponding diameters of bundled plants at cross sectional areas of 113, 200, 314 and 452 $\mathrm{mm}^{2}$ were found to be $12,16,20$ and $24 \mathrm{~mm}$, respectively. These bundled plants were fitted firmly in the stalk holder to simulate natural stand of stalk in the field. The holder is located at the lowest oscillating point where the equilibrium line is located. The experiments were conducted at different blade velocities of 1.50, 2.00, 2.50 and $3.10 \mathrm{~ms}^{-1}$ and for two types of blades viz., smooth edged and serrated blades. The initial angular displacements were fixed and corresponding cutting velocities were determined and all the experiments were replicated three times and the averages of the calculated cutting energy, cutting force and specific cutting energy were reported.

\section{Results and Discussion}

The effect of blade type, cutting velocity and stalk diameter or cross sectional area of black gram stalks on cutting energy were studied and the results obtained during the experiment trials are presented in Table 2. The experiments were carried out at a stalk moisture content of $22.52 \%$ (w.b.).

The results showed that the cutting energy decreased as the cutting velocity increased for both type of blades. The cutting energy for the both type of blades increased as the diameter or cross sectional areas of black gram stalks increased because of increase in stalk thickness, as blade had to cut more plant material. For smooth edge blade, the cutting energy was found to be varied from 2.98 to $18.06 \mathrm{~J}$. The maximum cutting energy of $18.06 \mathrm{~J}$ was observed at a cutting velocity of $1.50 \mathrm{~m} \mathrm{~s}^{-1}$ at $24 \mathrm{~mm}$ stalk diameter. The minimum value of cutting energy of $2.98 \mathrm{~J}$ was obtained at a cutting velocity of $3.10 \mathrm{~m} \mathrm{~s}^{-}$ ${ }^{1}$ at $12 \mathrm{~mm}$ stalk diameter.

In case of serrated blade, the cutting energy was ranged from 2.52 to $15.04 \mathrm{~J}$. The maximum cutting energy of $15.04 \mathrm{~J}$ was recorded at a cutting velocity of $1.50 \mathrm{~m} \mathrm{~s}^{-1}$ at stalk diameter of $24 \mathrm{~mm}$ whereas the minimum cutting energy of $2.52 \mathrm{~J}$ was observed at a cutting velocity of $3.10 \mathrm{~m} \mathrm{~s}^{-1}$ at 
stalk diameter of $12 \mathrm{~mm}$. The analysis of variance for cutting energy for black gram stalks is presented in Table 3. The statistical analysis of cutting energy shows that, the applied model is significant at 1 percent level of significance. The individual effect of the independent variables viz., cutting velocity, diameter and blade types had influenced the cutting energy and was significant at the 1 percent level of significance. Among the independent variables, the order of significance was highest for diameter of stalks or cross sectional areas of plants followed by cutting velocity and types of blade. Also, the interaction of all the variables were also affected the cutting energy values significantly. The standard deviation was found to be 0.047 with a mean value of 8.52 and co-efficient of variation is 0.556 per cent.

The data pertaining to the effect of cutting velocity, blade type and stalk diameter of black gram stalks on cutting force are given in Table 4.

It was observed that the cutting force decreased as the cutting velocity increased for both types of blades. It was also observed that the cutting force for smooth edge blade increased as the diameter or cross sectional area of black gram stalks increased. The same trend was also noticed for serrated type blade.

The serrated type of blade recorded lesser cutting force compared to that of smooth edge type blade at all cutting velocities and cross sectional areas or diameters of black gram stalks.

For smooth edge blade, the cutting force required to cut black gram stalks was ranged from 248.33 to $587.50 \mathrm{~N}$. The maximum value of cutting force of $752.50 \mathrm{~N}$ was recorded at a cutting velocity of $1.50 \mathrm{~m} \mathrm{~s}^{-1}$ at $24 \mathrm{~mm}$ stalk diameter while the minimum cutting force of $248.33 \mathrm{~N}$ was observed at a cutting velocity of $3.10 \mathrm{~m} \mathrm{~s}^{-1}$ at $12 \mathrm{~mm}$ stalk diameter. In case of serrated type blade, the cutting force was varied from 210.00 to $626.67 \mathrm{~N}$. At a cutting velocity of $1.50 \mathrm{~m} \mathrm{~s}^{-1}$ and for $24 \mathrm{~mm}$ stalk diameter, the maximum cutting force of $626.67 \mathrm{~N}$ was recorded. The lowest cutting force value of $210.00 \mathrm{~N}$ was found at a cutting velocity of $3.10 \mathrm{~m} \mathrm{~s}^{-1}$ and at stalk diameter of $12 \mathrm{~mm}$.

The statistical analysis of cutting force indicates that the applied model was significant at 1 percent level of significance. The independent variables viz., cutting velocity, diameter and blade types had influenced the cutting force at 1 percent level of significance. Also, the interaction of all the parameters were also affected the cutting force values significantly (Table 5). The standard deviation and co-efficient of variation were found to be 6.587 and 1.674 per cent with a mean value of 393.396 .

The results showed that the cutting energy and cutting force requirement were decreased as the cutting velocity increased for both type of blades whereas these values were increased as the diameter of black gram increased. The cutting energy and cutting force for the both type of blades decreased as the cutting velocity increases, this might have been due to the fact that, at low cutting velocity, the stalks become flattened and crushed and the cutting process was accompanied by large resistive forces. With increase in cutting velocity, the stalks were cut without flattening or crushing and the resistive forces decreased.

The cutting energy and cutting force required for cutting black gram stalks increased with increase in the diameter of black gram stalks as the diameter or cross sectional areas of black gram stalks increased which increased stalk thickness and blade had to cut more plant material.

The increase in cross sectional area of stalks offers more resistive force for cutting. Similar 
findings were reported by Kathirvel et al., (2009) and Yiljep and Mohammed (2005).

Among the two types of blades used for experiments and for selected variety of black gram, serrated type blade required less cutting energy and cutting force as compared to that of smooth edge type blade at all cutting velocities and diameters of stalks. This might have been due to the fact that, the serrations provided on the blade have better crop holding tendency at the time of cutting, which eliminates the slipping of stems during the process of cutting.

Table.1 Plan of experiments for pendulum type impact tester

\begin{tabular}{|c|c|c|c|}
\hline Crop & $\begin{array}{l}\text { Independent } \\
\text { parameters }\end{array}$ & Levels & Performance parameters \\
\hline \multirow[t]{10}{*}{ Black gram } & \multirow[t]{2}{*}{ Blades } & B-1(smooth edged blade) & Cutting energy \\
\hline & & B-2 (serrated blade) & Cutting force \\
\hline & \multirow[t]{4}{*}{ Velocity } & $\mathrm{V}-1 \quad(1.5 \mathrm{~m} / \mathrm{s})$ & \\
\hline & & $\mathrm{V}-2 \quad(2.0 \mathrm{~m} / \mathrm{s})$ & \\
\hline & & $\mathrm{V}-3 \quad(2.5 \mathrm{~m} / \mathrm{s})$ & \\
\hline & & $\mathrm{V}-4 \quad(3.1 \mathrm{~m} / \mathrm{s})$ & \\
\hline & \multirow{4}{*}{$\begin{array}{l}\text { Cross sectional area/ } \\
\text { Diameter of stalks }\end{array}$} & A-1 $\quad\left(113 \mathrm{~mm}^{2}\right) /(12 \mathrm{~mm})$ & \\
\hline & & A-2 $\quad\left(200 \mathrm{~mm}^{2}\right) /(16 \mathrm{~mm})$ & \\
\hline & & A-3 $\quad\left(314 \mathrm{~mm}^{2}\right) /(20 \mathrm{~mm})$ & \\
\hline & & A-4 $\quad\left(452 \mathrm{~mm}^{2}\right) /(24 \mathrm{~mm})$ & \\
\hline
\end{tabular}

Table.2 Pattern of cutting energy ( $\mathrm{J}$ ) for different cutting velocity, diameter of stalks and blade type for black gram stalks

\begin{tabular}{|c|c|c|c|c|c|}
\hline Blade types & $\begin{array}{c}\text { Cross sectional } \\
\text { area }\left(\mathbf{m m}^{\mathbf{2}}\right) / \\
\text { diameter }(\mathbf{m m})\end{array}$ & $\mathbf{V 1}(\mathbf{1 . 5})$ & $\mathbf{V 2}(\mathbf{2 . 0})$ & $\mathbf{V 3}(\mathbf{2 . 5})$ & $\mathbf{V 4}(\mathbf{3 . 1})$ \\
\hline \multirow{3}{*}{ Smooth edge blade } & $\mathrm{A} 1(113) / 12$ & 7.05 & 4.85 & 4.05 & 2.98 \\
\hline & $\mathrm{A} 2(200) / 16$ & 10.68 & 8.05 & 6.25 & 4.83 \\
\hline & $\mathrm{A} 3(314) / 20$ & 14.05 & 11.69 & 8.94 & 7.02 \\
\hline & $\mathrm{A} 4(452) / 24$ & 18.06 & 14.86 & 12.87 & 10.12 \\
\hline \multirow{3}{*}{ Serrated blade } & $\mathrm{A} 1(113) / 12$ & 5.98 & 4.52 & 3.63 & 2.52 \\
\hline & $\mathrm{A} 2(200) / 16$ & 8.54 & 7.5 & 5.75 & 3.89 \\
\hline & $\mathrm{A} 3(314) / 20$ & 11.5 & 10.5 & 8.26 & 5.85 \\
\hline & $\mathrm{A} 4(452) / 24$ & 15.04 & 13.5 & 11.63 & 7.8 \\
\hline
\end{tabular}


Table.3 Analysis of variance for cutting energy for black gram stalks

\begin{tabular}{|l|c|c|c|c|c|}
\hline \multicolumn{1}{|c|}{ Source } & $\begin{array}{c}\text { Sum of } \\
\text { Squares }\end{array}$ & Df & $\begin{array}{c}\text { Mean } \\
\text { Square }\end{array}$ & $\begin{array}{c}\text { F } \\
\text { Value }\end{array}$ & $\begin{array}{c}\text { p-value } \\
\text { Prob }>\text { F }\end{array}$ \\
\hline Model & 1487.148 & 31 & 47.973 & 21321.125 & $<0.0001$ \\
\hline $\begin{array}{c}\text { A-type of } \\
\text { blade }\end{array}$ & 37.275 & 1 & 37.275 & 16566.817 & $<0.0001$ \\
\hline B-velocity & 432.162 & 3 & 144.054 & 64023.944 & $<0.0001$ \\
\hline C-diameter & 971.633 & 3 & 323.878 & 143945.700 & $<0.0001$ \\
\hline AB & 8.036 & 3 & 2.679 & 1190.561 & $<0.0001$ \\
\hline AC & 6.429 & 3 & 2.143 & 952.561 & $<0.0001$ \\
\hline BC & 30.407 & 9 & 3.379 & 1501.593 & $<0.0001$ \\
\hline ABC & 1.2046 & 9 & 0.134 & 59.491 & $<0.0001$ \\
\hline Pure Error & 0.144 & 64 & 0.002 & & \\
\hline Cor Total & 1487.292 & 95 & & & \\
\hline Std. Dev. & & 0.047 & R-Squared & & 0.998 \\
\hline Mean & & 8.524 & Adj R-Squared & 0.996 \\
\hline C.V. \% & & 0.556 & Pred R-Squared & 0.997 \\
\hline PRESS & & 0.324 & Adeq Precision & 567.441 \\
\hline
\end{tabular}

Table.4 Pattern of cutting force $(\mathrm{N})$ for different cutting velocity, diameter of stalks and blade type for black gram

\begin{tabular}{|c|c|c|c|c|c|}
\hline \multirow[t]{2}{*}{ Blade types } & \multirow{2}{*}{$\begin{array}{c}\text { Cross sectional } \\
\operatorname{area}\left(\mathbf{m m}^{2}\right) / \\
\text { diameter }(\mathbf{m m})\end{array}$} & \multicolumn{4}{|c|}{ Velocity $(\mathrm{m} / \mathrm{s})$} \\
\hline & & V1 (1.5) & V2 (2.0) & V3 (2.5) & V4 (3.1) \\
\hline \multirow{4}{*}{ Smooth edge blade } & A1 (113)/12 & 587.50 & 404.17 & 337.50 & 248.33 \\
\hline & A2 (200)/16 & 667.50 & 503.13 & 390.63 & 301.88 \\
\hline & $\mathrm{A} 3(314) / 20$ & 702.50 & 584.50 & 447.00 & 351.00 \\
\hline & $\mathrm{A} 4(452) / 24$ & 752.50 & 619.17 & 536.25 & 421.67 \\
\hline \multirow{4}{*}{ Serrated blade } & A1 (113)/12 & 498.33 & 376.67 & 302.50 & 210.00 \\
\hline & A2 (200)/16 & 533.75 & 468.75 & 359.38 & 243.13 \\
\hline & $\mathrm{A} 3(314) / 20$ & 575.00 & 525.00 & 413.00 & 292.50 \\
\hline & $\mathrm{A} 4(452) / 24$ & 626.67 & 562.50 & 484.58 & 325.00 \\
\hline
\end{tabular}


Table.5 Analysis of variance for cutting force for black gram stalks

\begin{tabular}{|c|c|c|c|c|c|}
\hline Source & $\begin{array}{c}\text { Sum of } \\
\text { Squares }\end{array}$ & df & $\begin{array}{c}\text { Mean } \\
\text { Square }\end{array}$ & $\begin{array}{c}\text { F } \\
\text { Value }\end{array}$ & $\begin{array}{c}\text { p-value } \\
\text { Prob }>\text { F }\end{array}$ \\
\hline Model & 2192230.845 & 31 & 70717.124 & 1629.541 & $<0.0001$ \\
\hline A-A & 107207.484 & 1 & 107207.483 & 2470.391 & $<0.0001$ \\
\hline B-B & 1707170.049 & 3 & 569056.682 & 13112.825 & $<0.0001$ \\
\hline C-C & 296670.969 & 3 & 98890.323 & 2278.738 & $<0.0001$ \\
\hline AB & 33965.585 & 3 & 11321.861 & 260.890 & $<0.0001$ \\
\hline AC & 8975.976 & 3 & 2991.992 & 68.944 & $<0.0001$ \\
\hline BC & 17435.605 & 9 & 1937.289 & 44.641 & $<0.0001$ \\
\hline ABC & 20805.175 & 9 & 2311.686 & 53.268 & $<0.0001$ \\
\hline Pure Error & 2777.405 & 64 & 43.396 & & \\
\hline Cor Total & 2195008.250 & 95 & & & \\
\hline Source & $\begin{array}{c}\text { Sum of } \\
\text { Squares }\end{array}$ & df & Mean & F & p-value \\
\hline
\end{tabular}

\begin{tabular}{|l|l|l|l|}
\hline Std. Dev. & 6.587 & R-Squared & 0.998 \\
\hline Mean & 393.396 & Adj R-Squared & 0.998 \\
\hline C.V. \% & 1.674 & Pred R-Squared & 0.997 \\
\hline PRESS & 6249.161 & Adeq Precision & 146.208 \\
\hline
\end{tabular}

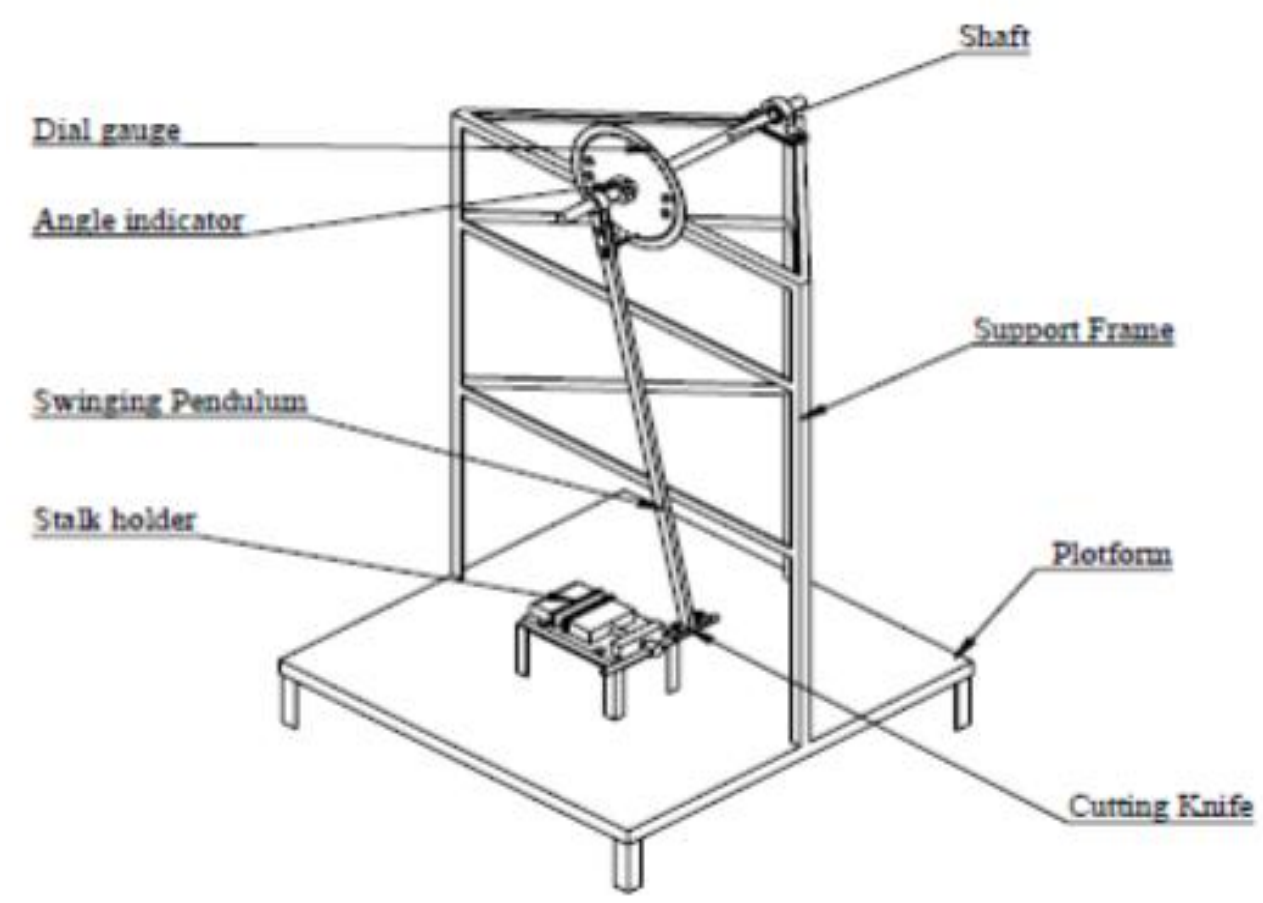

Fig.1 Schematic diagram of pendulum impact tester 


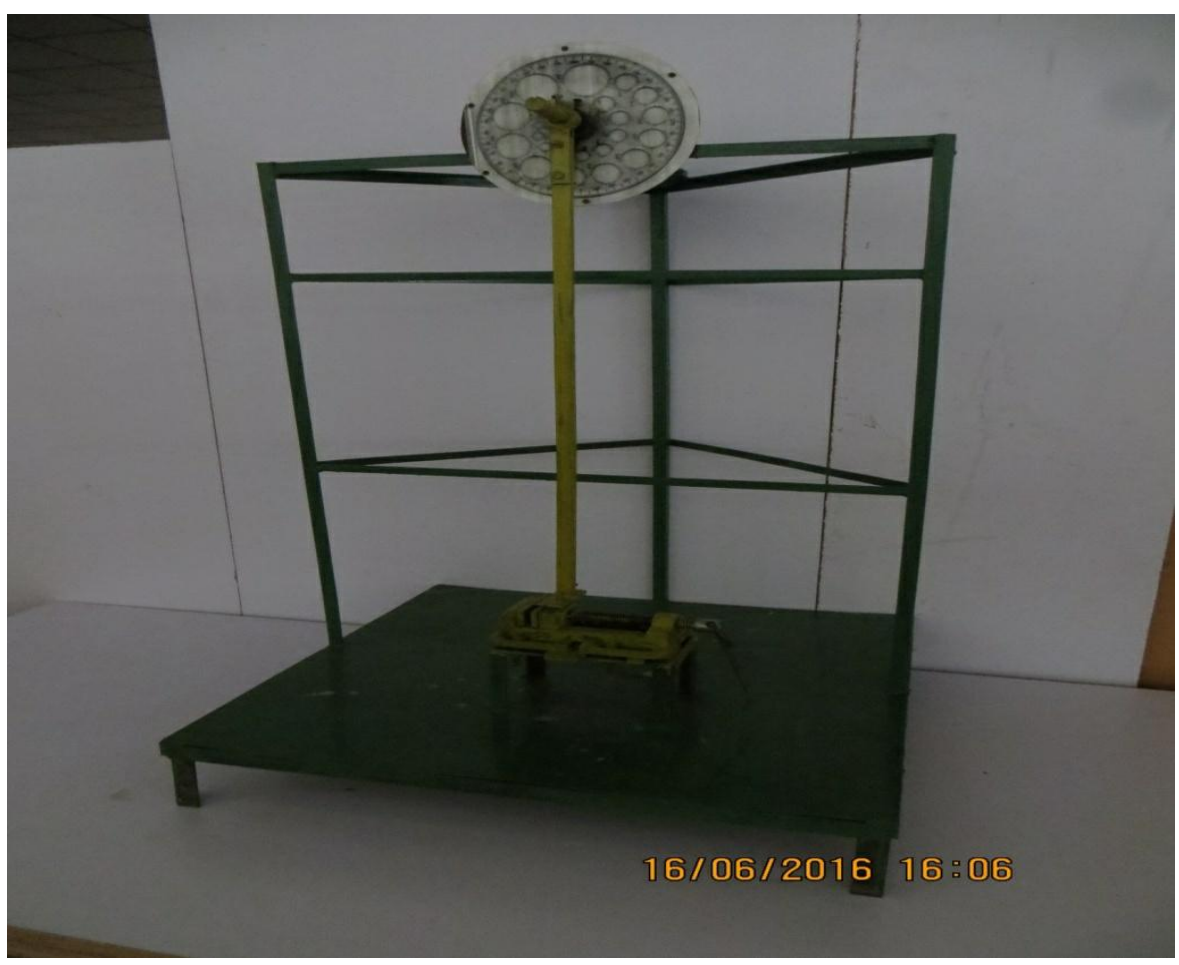

Plate.1 Pendulum impact tester

The trials on pendulum type impact tester were carried out as per the experimental plan. The effect of cutting velocity, diameter of stalks and types of blades on cutting energy and cutting force for black gram stalks were studied. For smooth edge blade, the cutting energy was found to be varied from 2.98 to $18.06 \mathrm{~J}$ whereas in case of serrated blade, the cutting energy was ranged from 2.52 to 15.04 J.

For smooth edge blade, the maximum value of cutting force of $752.50 \mathrm{~N}$ was recorded at a cutting velocity of $1.50 \mathrm{~m} \mathrm{~s}^{-1}$ at $24 \mathrm{~mm}$ stalk diameter while the minimum cutting force of $248.33 \mathrm{~N}$ was observed at a cutting velocity of $3.10 \mathrm{~m} \mathrm{~s}^{-1}$ at $12 \mathrm{~mm}$ stalk diameter.

In case of serrated type blade, the cutting force was varied from 210.00 to $626.67 \mathrm{~N}$. At a cutting velocity of $1.50 \mathrm{~m} \mathrm{~s}^{-1}$ and for $24 \mathrm{~mm}$ stalk diameter, the maximum cutting force of 626.67 $\mathrm{N}$ was recorded. The lowest cutting force value of $210.00 \mathrm{~N}$ was found at a cutting velocity of $3.10 \mathrm{~m} \mathrm{~s}^{-1}$ and at stalk diameter of $12 \mathrm{~mm}$.

\section{References}

Chakraverty, A., Singh, P. R., Raghavan, G. S. V. and Ramaswamy, H. S., 2003, Handbook of postharvest technology. $1^{\text {st }}$ edn, Marcel Dekker Inc, New York

Dange, A. R., Thakare, S. K., Bhaskarrao, I. and Umarfarooq, M., 2012, Design of tractor front mounted pigeon pea stem cutter. J. Agric. Technol., 8(2): 417-433.

Dauda, S. M., Ahmad, D., Khalina, A. and Jamarei, O., 2015, Effect of cutting speed on cutting torque and cutting power of varying kenaf-stem diameters at different moisture contents. Pertanika J. Trop. Agric. Sci., 38 (4): $549-561$.

Kathirvel, K., Ramesh, D., Thambidurai, S. and Jesudas, D. M., 2009, Ergonomics of self propelled power weeders as influenced by forward speed and terrain condition. Agric. Mechan. Asia, Africa, latin America 40(4): 28-32.

Manthesh, 2006, Development of mini 
combine harvester for pulse crops. Unpublished Ph.D. thesis submitted to TNAU, Coimbatore

Yilmaz, D., Akinci, I. and Cagiran, M. I., 2008, Effect of some threshing parameters on sesame separation. Agric.
Engg. Int.: CIGR E-J, 10: 1-8. Yore, M. W., Jenkins, B. M. and Summers, M. D., 2002, Cutting properties of rice straw. ASAE. Annual Int. Meeting / CIGR XV the World Congress. USA, 28-31 July: 1-9.

\section{How to cite this article:}

Sushilendra, M. Veerangouda, Bhavya and Manjunatha. K. 2020. Effect of Blade Type, Cutting Velocity and Stalk Cross Sectional Area of Black Gram Stalks on Cutting Energy and Cutting Force. Int.J.Curr.Microbiol.App.Sci. 9(06): 650-659.

doi: https://doi.org/10.20546/ijcmas.2020.906.083 